\title{
A STUDY ON PULMONARY INVOLVEMENT IN CHRONIC RHEUMATOID ARTHRITIS WITH CHEST X- RAY AND SPIROMETRY IN A TEACHING HOSPITAL
}

\author{
Rajeev Anand ${ }^{1}$, Baiju Sam Jacob², Balachandran Jayachandra Rao ${ }^{3}$ \\ ${ }^{1}$ Associate Professor, Department of Radiodiagnosis, Travancore Medical College, Kollam, Kerala. \\ 2 Professor, Department of General Medicine, Travancore Medical College, Kollam, Kerala. \\ 3 Professor, Department of Pulmonary Medicine, Travancore Medical College, Kollam, Kerala.
}

\begin{tabular}{l}
\hline ABSTRACT \\
RACKGROUND \\
Rheumatoid arthritis (RA) is a chronic systemic inflammatory disorder with a $0.5 \%-2 \%$ prevalence in the general population. \\
through the use of chest x-ray and spirometry.
\end{tabular}

\section{MATERIALS AND METHODS}

The present study comprised of patients with RA who attended Rheumatology clinic in the Dept. of Medicine, Travancore Medical College, Kollam, Kerala. These patients were clinically evaluated and screened with chest x-ray and spirometry.

\section{RESULTS}

A total of 124 RA patients underwent assessments. $23 \%$ of the patients reported a history of smoking. Chest x-ray was abnormal in $43 \%$ and spirometry was abnormal in $40.3 \%$. Comparing the patients in whom both test results were normal $(n=54)$, those in whom abnormal test results were obtained $(n=70)$, a statistically significant difference was found between the two groups. There were signs of airway disease in nearly half of the patients with minimal or no history of tobacco smoke exposure.

\section{CONCLUSION}

Pulmonary involvement in RA can be identified through simple and inexpensive diagnostic methods. Study suggests that RA patients should be screened for lung involvement, even if no respiratory symptoms are presented.

\section{KEYWORDS}

Rheumatoid Arthritis, Pulmonary Involvement, Chest X-Ray, Spirometry.

HOW TO CITE THIS ARTICLE: Anand R, Jacob BS, Rao BJ. A study on pulmonary involvement in chronic rheumatoid arthritis with chest $x$-ray and spirometry in a teaching hospital. J. Evolution Med. Dent. Sci. 2018;7(04):495-498, DOI: 10.14260/jemds/2018/110

\section{BACKGROUND}

Rheumatoid arthritis (RA) is a systemic inflammatory disorder with a $0.5 \%-2 \%$ prevalence in the general population. ${ }^{1}$ It has been proposed that patients with RA should be screened for ILD through the use of chest x-rays and pulmonary function tests (PFTs). ${ }^{2}$ Depending on the screening method used, up to $50 \%$ of chronic patients exhibit pulmonary involvement. The majority of cases have a subclinical presentation. ${ }^{3}$ Recent studies have reported high mortality rates in patients with usual interstitial involvement, a severe form of interstitial lung disease (ILD). ${ }^{4}$ Studies evaluating chest $x$-rays in RA patients have detected abnormalities in only $1.6 \%-6 \%$ of patients, ${ }^{5}$ whereas more recent studies have reported higher frequencies ranging from $19 \%$ to $29 \%{ }^{6}$ The x-ray devices currently available offer better imaging evaluation, because of advanced image analysis tools and newer acquisition techniques such as digital radiography 7 than do conventional devices. ${ }^{8}$

'Financial or Other Competing Interest': None.

Submission 13-12-2017, Peer Review 07-01-2018,

Acceptance 13-01-2018, Published 22-01-2018.

Corresponding Author:

Rajeev Anand,

Associate Professor,

Department of Radiodiagnosis,

Travancore Medical College,

Kollam, Kerala.

E-mail: rajeevradiology@gmail.com

DOI: $10.14260 /$ jemds/2018/110

\section{(c) (i) $\odot$}

Although, HRCT of the chest is more sensitive than is chest $\mathrm{x}$-ray, the former detecting $50 \%$ of abnormalities, ${ }^{9}$ it is not recommended as a screening tool for pulmonary involvement in patients with RA, because the disease is highly prevalent and lung abnormalities in RA patients are often minimal. ${ }^{2}$ In a recent study involving 356 patients newly diagnosed with RA, Mori et al found that only $15 \%$ had relevant abnormalities on HRCT scans ${ }^{10}$ suggesting that HRCT should not be routinely performed after RA has been diagnosed.

Spirometry is an inexpensive tool for grading the severity of pulmonary impairment and can be applied on a large scale. Studies employing spirometry have detected abnormalities, mainly obstructive and restrictive patterns, in approximately $30 \%$ of patients with RA. ${ }^{1}$ Although, low DLCO is a reliable early marker of pulmonary impairment, 11 the diagnostic tool required in order to determine DLCO is not widely available.

Our study insists use of chest x-ray and spirometry to provide relevant disease information regarding lung involvement in patients with RA. Therefore, we performed a screening evaluation in order to assess the signs of lung disease in patients with chronic RA. We also evaluated the correlations among imaging abnormalities, PFT findings and smoking.

\section{Aim}

To determine the use of simple investigations like chest $x$-ray and spirometry to detect pulmonary involvement in patients with chronic rheumatoid arthritis (RA). 


\section{MATERIALS AND METHODS}

This is a descriptive study done between May 2016 and May 2017. Patients with chronic RA undergoing regular follow-up evaluations at the Rheumatology Clinic and General Medicine Department of Travancore Medical College, Kollam, a teaching hospital in Kerala were evaluated. All of them had been diagnosed with RA on the basis of the criteria established in 1987 by the American College of Rheumatology. ${ }^{12}$ Patients were excluded if they were below five years after diagnosis with irregular treatment or were unable to perform spirometry manoeuvres or did not complete the tests. Smoking status was characterised as "never smoker," "ex-smoker" or "current smoker." All participating patients gave written informed consent.

Chest x-rays were obtained with a digital radiography system employing a selenium detector. Images were acquired in postero-anterior and lateral views at maximum inspiration. Lungs were considered to be hyperinflated if any 2 of the following 3 criteria were met: diaphragm flattening; hemidiaphragm below the 10th posterior rib; and enlargement of the retrosternal space. ${ }^{13}$ Lung volume was considered to be diminished if the hemidiaphragm was above the 9th posterior rib. Parenchymal abnormalities were defined as the presence of an alveolar pattern; interstitial nodular opacities; interstitial reticular opacities; isolated lung nodule or mass; a likely calcified nodule; multiple nodules; cavitation; opacities from fibrotic scarring; lobar atelectasis; segmental atelectasis; or isolated hyperinflation. ${ }^{13}$ The main profiles observed on the chest x-rays were hyperinflation, interstitial patterns and volume loss.

Pre- and post-bronchodilator spirometry were performed. The classification and grading of the results were based on the American Thoracic Society/ European Respiratory Society guidelines ${ }^{14}$

- Obstructive disease-defined as an $\mathrm{FEV}_{1} / \mathrm{FVC}$ ratio < lower limit of normal (LLN) with an FVC $\geq$ LLN (patients with an $\mathrm{FEV}_{1} / \mathrm{FVC}$ ratio < LLN and an FVC < LLN in the pre-bronchodilator tests, but with normalisation of FVC after reversibility testing also being included in this category.

- Possible restrictive disease-defined as an $\mathrm{FEV}_{1} / \mathrm{FVC}$ ratio $\geq$ LLN with an FVC < LLN and no post-bronchodilator normalisation of FVC.

We used the chi-square test ( $\chi^{2}$ statistic) to examine independence between categorical variables and we calculated the relative risk (RR) with its corresponding 95\% confidence interval. All reported values are two-sided and have not been adjusted for multiple comparisons. The level of statistical significance was set at $\mathrm{p}<0.05$. All statistical analyses were performed using OpenEpi and Stata, version 13.

\section{RESULTS}

Out of the patients being followed at the Rheumatology Clinic during the study period, 124 underwent complete assessment and were included in the study. As can be seen in Table 1, the mean age was 52 years and $65 \%$ of the patients were female. The mean disease duration was 14 years. $23 \%$ of the population reported smoking. 33\% were former smokers. Of 124 patients evaluated, 77 (62\%) were RF positive.
We stratified the patients by test results: those with normal chest $x$-ray and spirometry findings $(n=54)$ and those with abnormalities on any of those tests $(n=70)$. When we compared those two groups, we found that significant abnormalities were more common in males, elderly patients, RF-positive patients and current smokers.

Spirometry was normal in $59.7 \%$ of the patients (Table 2). We observed obstructive pattern in $13.7 \%$ and restrictive pattern in $18.5 \%$ and mixed patterns in $8.1 \%$. Chest $\mathrm{x}$-rays were normal in $71(57.3 \%)$ of the patients; hyperinflation was present in $17.7 \%$; interstitial pattern was observed in $16.1 \%$ ); volume loss was observed in $3.2 \%$ and miscellaneous abnormalities were observed in the remaining 5.7\% (Table 3). Only $43.5 \%$ of the patients had normal chest x-rays and normal spirometry findings. Abnormalities on chest x-rays alone were more common than were abnormalities on spirometry alone.

\begin{tabular}{|c|c|c|}
\hline Characteristic & No. of Patients & Percentage \\
\hline Male & 43 & 34.7 \\
\hline Female & 81 & 65.3 \\
\hline Mean Age (yrs.) & 52 & \\
\hline RF-positive & 77 & 62 \\
\hline Mean Disease Duration (yrs.) & 14 & 22.5 \\
\hline Smoking Status (Current) & 28 & 29.8 \\
\hline Smoking Status (Ex) & 37 & \\
\hline \multicolumn{2}{|c|}{ Table 1 } \\
\hline
\end{tabular}

\begin{tabular}{|c|c|}
\hline Spirometry Findings & No. of Patients \\
\hline Normal & $74(59.7 \%)$ \\
\hline Obstructive & $17(13.7 \%)$ \\
\hline Restrictive & $23(18.5 \%)$ \\
\hline Mixed & $10(8.1 \%)$ \\
\hline \multicolumn{2}{|c|}{ Table 2 } \\
\hline
\end{tabular}

\begin{tabular}{|c|c|}
\hline X-Ray Findings & No. of Patients \\
\hline Hyperinflation & $22(17.7 \%)$ \\
\hline ILD Pattern & $20(16.1 \%)$ \\
\hline Volume Loss & $4(3.2 \%)$ \\
\hline Miscellaneous & $7(5.7 \%)$ \\
\hline Total & $\mathbf{5 3 ( 4 2 . 7 \% )}$ \\
\hline \multicolumn{2}{|c}{ Table 3 } \\
\hline
\end{tabular}

\section{DISCUSSION}

We found that spirometry and chest $\mathrm{x}$-rays frequently detected lung abnormalities in patients with RA indicating that given their feasibility and availability, these inexpensive screening tools should be incorporated into our practice as routine tests for RA patients. The combined analysis with chest $\mathrm{x}$-ray and spirometry revealed abnormalities in $56.5 \%$ of the patients in our sample, suggesting that pulmonary involvement is easily diagnosed in RA patients treated at our teaching hospital. Morrison et al used chest x-rays and PFTs to evaluate $104 \mathrm{RA}$ patients and reported abnormalities in $53.8 \%$, mostly pleural disease (in 30\%) and tuberculosis (in $44 \%) .{ }^{6}$ When patients with a smoking history or concomitant lung disease were excluded, the authors found abnormalities in $19.2 \%$ of the patients.

Cortet et al compared PFTs and HRCT in screening for pulmonary involvement in 68 consecutive patients with RA. ${ }^{1}$ With spirometry, the authors detected lung abnormalities in $32 \%$ of the patients, observing obstructive patterns in $20 \%$ 
and a restrictive pattern in $12 \%$. Using HRCT, the same authors detected lung abnormalities in $80.9 \%$ of the patients: bronchiectasis in $30.5 \%$; pulmonary nodules in $28 \%$; air trapping in 25\%; ground glass attenuation in 17.1\%; honeycombing in $2.9 \%$; and pleural effusion in $1.5 \%$. In our study, we observed abnormalities by spirometry in $40.3 \%$ of the patients (obstructive pattern in $13.7 \%$ and restrictive pattern in $18.5 \%$ ). We also noted that lung abnormalities on chest $\mathrm{x}$-rays were common (present in $42.7 \%$ of the patients) including hyperinflation (in 17.7\%) and an interstitial pattern (in 16.1\%). The differences in the frequencies observed on chest $\mathrm{x}$-rays and those detected by HRCT might be attributed to the better sensitivity of HRCT in comparison with chest $\mathrm{x}$ ray. Those authors observed statistically significant differences between patients with and without interstitial lung abnormalities in terms of age, dyspnoea, smoking and spirometry findings. The significant difference in dyspnoea might be explained by the inclusion criteria used by the authors. For example, HRCT of the chest was used only in patients in whom it was clinically indicated, which effectively excluded patients with asymptomatic ILD, thereby introducing a selection bias.

Most of the abnormalities seen on spirometry were mild and the prevalence of normal spirometry was high even when chest x-ray was abnormal. Our findings are consistent with those of a recent study by Mohd. Noor et al,15 who reported that although $92 \%$ of the 63 RA patients evaluated exhibited no dyspnoea $95 \%$ and $71 \%$ of those patients respectively showed lung abnormalities on PFTs and HRCT. Therefore, in patients with RA, it is not advisable to wait until symptoms develop to perform the pulmonary evaluation.

In our study, most of the patients whose chest x-rays showed abnormalities exhibited restrictive spirometry findings. The fact that some RA patients have airway and parenchymal lung disease, which could lead to normal spirometry findings was also noted. The latter might explain why spirometry findings can be normal in patients showing hyperinflation on chest x-rays, because mild interstitial abnormalities are not expected to be diagnosed by chest $\mathrm{x}$ ray. We found an obstructive pattern on spirometry to be uncommon among patients whose chest x-ray showed an interstitial pattern, just as we expected a restrictive pattern on spirometry to be an uncommon finding in patients whose chest x-ray showed hyperinflation.

Another interesting finding of the present study is that the prevalence of abnormalities on chest x-rays was $42.7 \%$, which is much higher than the $6 \%$ previously described.(6-8) This might be attributed to a number of factors: selection bias, because our patients were invited by a physician to undergo lung screening in our method of chest x-ray evaluation analysing hyperinflation and categorising the findings could differ from that employed in other studies and the possibly superior diagnostic performance of digital x-ray systems, ${ }^{16}$ which might provide better visualisation of peripheral lung structures than do conventional $\mathrm{x}$-ray systems. $^{8}$ We believe that the two last factors represent the most likely explanations for the relatively high prevalence of abnormalities on chest x-rays in our study, given that the prevalence of abnormalities on spirometry was similar between our study and previous studies. 12 Even if we excluded the volume loss pattern our abnormality frequency would be $39.5 \%$, well above what is expected. Zrour et al evaluated chest x-rays in $75 \mathrm{RA}$ patients and observed abnormalities in $29.3 \% .^{3}$ Given that we identified parenchymal abnormalities in $16.1 \%$ of our patients and lung volume abnormalities in $18 \%$, we believe that the discrepancy between our findings and those of the authors cited above is attributable to the fact that we included hyperinflation in our analysis of the chest x-ray findings, as was not done in the Zrour et al study. ${ }^{3}$

Our study has some limitations. First, this study was based on a sample of patients treated at the rheumatology clinic of a tertiary care referral centre. Therefore, it is likely that the patients recruited constituted a population with more advanced or difficult-to-treat disease, which could represent a selection bias. Furthermore, because we aimed to perform simple, objective, unbiased measurements we did not perform echocardiograms. Therefore, chronic heart failure could have been misidentified as ILD. Moreover, because abnormalities were not evaluated by chest HRCT, our study might have underestimated the frequency of pulmonary involvement in RA patients, although our aim was to assess how simple diagnostic tests would be useful in patients with RA.

\section{CONCLUSION}

RA is a common systemic inflammatory disorder and RAassociated lung disease is not uncommon. Studies have shown that pulmonary involvement is present in up to $50 \%$ of all patients with RA.(2,3) Given these observations routine screening by HRCT scan and PFTs is not recommended, 5 because the number of patients requiring such screening would be large, making this strategy unfeasible. However, RA-associated pulmonary involvement is a source of substantial morbidity and mortality for affected patients ${ }^{5}$ and disease progression has been described in approximately $60 \%$ of cases, 11 which necessitates the implementation of an appropriate simple screening strategy like CXR and spirometry.

\section{REFERENCES}

[1] Cortet B, Perez T, Roux N, et al. Pulmonary function tests and high resolution computed tomography of the lungs in patients with rheumatoid arthritis. Ann Rheum Dis 1997;56(10):596-600.

[2] Kim EJ, Collard HR, King TE. Rheumatoid arthritisassociated interstitial lung disease: the relevance of histopathologic and radiographic pattern. Chest 2009;136(5):1397-405.

[3] Zrour SH, Touzi M, Bejia I, et al. Correlations between high-resolution computed tomography of the chest and clinical function in patients with rheumatoid arthritis. Prospective study in 75 patients. Joint Bone Spine 2005;72(1):41-7.

[4] Kim EJ, Elicker BM, Maldonado F, et al. Usual interstitial pneumonia in rheumatoid arthritisassociated interstitial lung disease. Eur Respir J 2010;35(6):1322-8.

[5] Gabbay E, Tarala R, Will R, et al. Interstitial lung disease in recent onset rheumatoid arthritis. Am J Respir Crit Care Med 1997;156(2 Pt 1):528-35. 
[6] Morrison SC, Mody GM, Benatar SR, et al. The lungs in rheumatoid arthritis--a clinical, radiographic and pulmonary function study. Afr Med J 1996;86(7):82933.

[7] Schaefer-Prokop C, Uffmann M, Eisenhuber E, et al. Digital radiography of the chest: detector techniques and performance parameters. J Thorac Imaging 2003;18(3):124-37.

[8] Ramli K, Abdullah BJ, $\mathrm{Ng} \mathrm{KH}$, et al. Computed and conventional chest radiography: a comparison of image quality and radiation dose. Australas Radiol 2005;49(6):460-6.

[9] Crestani B. The respiratory system in connective tissue disorders. Allergy 2005;60(6):715-34.

[10] Mori S, Koga Y, Sugimoto M. Different risk factors between interstitial lung disease and airway disease in rheumatoid arthritis. Respir Med 2012;106(11):15919.

[11] Gochuico BR, Avila NA, Chow CK, et al. Progressive preclinical interstitial lung disease in rheumatoid arthritis. Arch Intern Med 2008;168(2):159-66.
[12] Arnett FC, Edworthy SM, Bloch DA, et al. The American Rheumatism Association 1987 revised criteria for the classification of rheumatoid arthritis. Arthritis Rheum 1988;31(3):315-24.

[13] Goodman LR, Felson B. Felson's principles of chest roentgenology. A programmed text. $3^{\text {rd }}$ edn. Philadelphia: Saunders Elsevier 2007:52-3.

[14] Pellegrino R, Viegi G, Brusasco V, et al. Interpretative strategies for lung function tests. Eur Respir J 2005;26(5):948-68.

[15] Noor MN, Shahrir MMS, Shahid MS, et al. Clinical and high resolution computed tomography characteristics of patients with rheumatoid arthritis lung disease. Int J Rheum Dis 2009;12(2):136-44.

[16] Garmer M, Hennigs SP, Jäger $H J$, et al. Digital radiography versus conventional radiography in chest imaging: diagnostic performance of a large-area silicon flat-panel detector in a clinical CT-controlled study. AJR Am J Roentgenol 2000;174(1):75-80. 